\title{
Determination of glycaemic response of a novel cane sugar product incorporated with Phyllanthus emblica and Zingiber officinale extracts
}

\author{
Chathuranga Hasithi Samarasinghe ${ }^{1^{*}}$, Madhura Arunoda Jayasinghe ${ }^{1}$, \\ Senadheera Pathirannehelage Anuruddhika Subhashinie Senadheera ${ }^{2}$, Isuru \\ Wijesekara $^{1}$, Binosha Fernando ${ }^{3}$, Kamburawala Kankanamge Don Somathilaka \\ Ranaweera $^{1} \&$ Nirodha Heshan Bandara Wilamune ${ }^{1}$
}

${ }^{1}$ Department of Food Science and Technology, Faculty of Applied Sciences, University of Sri Jayewardenepura, Gangodawila, Nugegoda Sri Lanka; ${ }^{2}$ Department of Biochemistry, Faculty of Medicine and Allied Sciences, Rajarata University of Sri Lanka, Saliyapura, Sri Lanka; ${ }^{3}$ Centre of Excellence for Alzheimer's Disease Research and Care, School of Medical and Health Sciences, Edith Cowan University, Australia

\begin{abstract}
Introduction: The use of natural plant extracts to reduce blood glucose response has been practised from ancient times, although their industrial applications are rare. For the convenience of typical cane sugar consumers, selected tropical plant extracts were incorporated with cane sugar to make a low glycaemic sugar product. Methods: This study compared the glycaemic responses of a commercially available product (Product 1) containing seven herbal extracts; fenugreek (Trigonella foenumgraecum), turmeric (Curcuma longa), black pepper (Piper nigrum), ginger (Zingiber officinale), cinnamon (Cinnamomum verum), gooseberry (Phyllanthus emblica) and pomegranate (Punica granatum) against a novel product (Product 2) that was made by incorporating only two plant extracts that were cheaper and readily available in the local market - gooseberry (Phyllanthus emblica) and ginger (Zingiber officinale). Extracts were incorporated with cane sugar to make a series of crystallised solid sugar products and the formulae with the best sensory attributes was selected (Product 2). The glycaemic indices of both products were determined by standardised methodology using 12 healthy volunteers in a randomised crossover study. Results: The mean glycaemic index (GI) value for sugar in Product 1 was $49 \pm 9$ and in Product 2 was $38 \pm 9$. Both results elicited significantly $(p<0.05)$ lower GI values than normal cane sugar $(\mathrm{GI}=65)$. The novel cane sugar product (Product 2) was far more superior compared to the commercially available product (Product 1) in reducing blood glucose response. Conclusion: Incorporation of suitable herbal extracts to cane sugar and foods like rice and wheat flour may be a suitable option to reduce their glycaemic impact.
\end{abstract}

Keywords: Cane sugar, diabetes, ginger, glycaemic index, gooseberry

\footnotetext{
*Corresponding author: Chathuranga Hasithi Samarasinghe

Department of Food Science and Technology, Faculty of Applied Sciences,

University of Sri Jayewardenepura, Gangodawila, Nugegoda Sri Lanka

Tel: +94 71215 2911; E-mail: hasithivvas@gmail.com

doi: https://doi.org/10.31246/mjn-2019-0063
} 


\section{INTRODUCTION}

Diabetes mellitus is very common among ageing people and two thirds of the global diabetic population are living in developing countries. Among them, Sri Lanka is one of the countries in the world that has a high diabetes prevalence rate (Katulanda, Sheriff \& Matthews, 2009). Diabetes is the hyperglycaemic condition caused as a result of defects in insulin secretion, insulin action or both, and is considered as a metabolic disorder (Goldenberg \& Punthakee, 2013). In a healthy adult, blood glucose level is managed primarily by insulin, which converts glucose into energy to function the activities of the body. However, people with diabetics no longer produce insulin or do not produce sufficient amount of it to convert blood glucose into energy (Kharroubi \& Darwish, 2015; Röder et al., 2016).

Among the nutrients, carbohydrate is the most important nutrient that contributes to the conversion of glucose into energy. Therefore, it is advisable that diabetic patients select low glycaemic index (GI) carbohydrates to avoid the release of high quantities of glucose into the blood (Eleazu, 2016).

Although a change in diet and exercise can help manage diabetes, most patients in Sri Lanka ultimately require oral anti-diabetic drugs to manage the disease (Kumara \& Siriwardena, 2016; Valitutto, 2008). This may be due to the high consumption of cane sugar incorporated foods. According to Wrolstad (2011), consumer food items such as biscuits, cakes, chewing gums, carbonated beverages, ready to serve drinks, jams and spreads are rich in sugar. Sugars are used in these items mainly as sweeteners, as well as to improve their palatability and as a preservative. Hence, formulation and consumption of low glycaemic impact sugar products has been a topic of interest for many years.

A variety of traditional herbs, spices or their mixers used in Sri Lanka have beneficial effects on diabetes and they are non-prescription treatments for diabetes. However, their efficacy has yet to be investigated. Here, we incorporated herbal extracts to cane sugar with an aim to suppress its glycaemic impact.

In this study, only two edible plant sources were selected - gooseberry (Phyllanthus emblica) and ginger (Zingiber officinale), for the formulation of a novel product, considering their higher efficacy in traditional diet therapies, as well as their cost effectiveness; enabling these products to be made at the commercial level with a lower price. These plant sources are highly rated for their health benefits in Ayurvedic medicine and are popular among communities in South and South-East Asia as "nutritive" plant foods. The incorporation of such active food ingredients can readily induce the activity level of insulin and its sensitivity in cells, as shown by a previous study (Gunathilaka \& Ranaweera, 2018).

Gooseberry (Phyllanthus emblica) is popular for its high vitamin C content, which stimulates the pancreas and enables it to secrete insulin, thus reducing blood sugar level (Patel \& Goyal, 2011). It also prevents aggregation and insolubilisation of lens proteins (development of secondary complications of diabetes, including cataract) caused by hyperglycaemia (Daisy, Averal \& Modilal, 2005; Suryanarayan et al., 2007). The tannoids and tannins of Phyllanthus emblica are potent inhibitors of aldose reductase (AR), thus making them potential drugs for non-insulin dependent diabetics by enhancing glucose uptake and inhibiting adipogenesis (Modak et al., 2007). In addition, the presence of antioxidants neutralises free radicals, which is effective in preventing, as well as reducing 
the severity of diabetic complications (Modak et al., 2007). Further researches by Akhtar et al. (2011) and Shah et al. (2005) concluded that gooseberry as a supplement, is effective in reducing fasting and post-prandial blood glucose levels and glycated haemoglobin (HbA1c) levels.

Ginger (Zingiber officinale) is abundant with gingerol, shogaols, zingerone and paradol, which are all potent bioactive compounds (Choudhari \& Kareppa, 2013). A study suggested that ginger has a therapeutic benefit in lowering fasting serum glucose level in Type 2 diabetes patients (Andallu, Radhika \& Suryakantham, 2003). Although it remains uncertain which bioactive compound in ginger is causing this anti-diabetic efficacy, it is likely that its predominant pungent compound, 6-gingerole, is responsible for this (Choudhari \& Kareppa, 2013).

The synergistic effect of these two plant sources on diabetics has yet to be investigated. Thus, the current work aims to understand the synergy of gooseberry and ginger on glycaemic responses and to determine whether tropical plant food extracts can be incorporated into sugar to lower its glycaemic impact, while providing the best sensory attributes. Findings of this study will be useful in producing sugar substitutes which would have minimal impact in elevating blood glucose level.

\section{MATERIALS AND METHODS}

\section{Chemicals list}

Glucose oxidase-peroxidase kit (Biolabo, France), ethanol (BDH Anala R VWR International Ltd. Poole, England EC Label: 200-578-6), D(+)-Glucose (BDH Anala R VWR International Ltd, Poole, BH 15 1TD, England), sodium fluoride standard solution (Vishna chemicals, India).

\section{Ethical clearance}

Ethical clearance was obtained from the ethical review committee of the Faculty of Medicine, University of Sri Jayewardenepura, Sri Lanka under the reference no: $21 / 18$.

\section{Preparation of the sugar products}

Product 1- Commercially available product

The commercialised sugar product, DiaBliss Herbal Sugar (DHS) is formed by Diabliss Consumer Products Pvt Ltd, incorporating seven herbal extracts, namely fenugreek (Trigonella foenum-graecum), turmeric (Curcuma longa), black pepper (Piper nigrum), ginger (Zingiber officinale), cinnamon (Cinnamomum verum), gooseberry (Phyllanthus emblica) and pomegranate (Punica granatum) (Chockaligam et al., 2018).

\section{Product 2- Novel sugar product}

Indian gooseberry (Phyllanthus emblica) fruits and ginger (Zingiber officinale) rhizomes were ground with minimum amount of water (200g:125ml) and extracts were filtered using 20-25 $\mu \mathrm{m}$ (No.4 Watman) filter papers to get filtrates. Then a series of cane sugar concentration solutions with different brix values were made ranging from brix $16^{\circ}$ to $18^{\circ}$ (Table 1 ).

These solutions were heated to $115^{\circ} \mathrm{C}$ and allowed to cool down while stirring well. At $100^{\circ} \mathrm{C}$ and $90^{\circ} \mathrm{C}$, gooseberry and ginger extracts were mixed respectively in a particular ratio (Table 1). Mixtures were cooled down further and the final crystallised sugar was dried for three hours at $50^{\circ} \mathrm{C}$.

\section{Sample size determination for sensory evaluation and for intervention}

According to BS ISO13299:2003, descriptive panels may have '8-12 
Table 1. Initial brix values and herbal extract ratios

\begin{tabular}{ccc}
\hline Trial sample number & Initial brix value & Herbal extract ratio (Gooseberry:Ginger) \\
\hline 1 & $16^{0}$ & $2: 2$ \\
2 & $16^{0}$ & $4: 2$ \\
3 & $16^{0}$ & $6: 2$ \\
4 & $16^{0}$ & $8: 2$ \\
5 & $17^{0}$ & $2: 2$ \\
6 & $17^{0}$ & $4: 2$ \\
7 & $17^{0}$ & $6: 2$ \\
8 & $17^{0}$ & $8: 2$ \\
9 & $18^{0}$ & $2: 2$ \\
\hline
\end{tabular}

assessors' or more. They can either have as few as four (in consensus profiling) or as many as 20 to 30 when the purpose is to test for taints, to which only a minority may be sensitive. Therefore, this sensory evaluation was carried out by a semi-trained panel [discriminative and communicative (D\&C) panel] of 30 individuals.

Sample size for the intervention should be a minimum of nine with a margin of error of six units for continuous outcome $n=\left(Z_{\sigma} / E\right)^{2}$ (Sullivan, 2019; Röhrig et al., 2010).

\section{Recruitment of panelists for sensory evaluation}

When selecting for panelists, criteria that were considered included interest and motivation, ability to memorise and communicate sensory impressions, availability for panel sessions, capacity to concentrate and honesty in reporting sensations, promptness, good health, ability to discriminate the specific characteristics studied and engagement for the duration of the study (BS ISO13299:2003) (ISO, 2003). Furthermore, we made sure we did not take respondents suffering from diseases such as colds, diabetes, mouth cancers, as well as those with addictions towards smoking, alcoholic beverages, chewing beetles et cetera. Finally, the panelists should not have been exposed to any drug courses for a long time.

\section{Sensory analysis}

A sensory analysis was done for sensory parameters - appearance, odour, colour, taste and overall acceptability, with respect to six different chosen trial samples (Table 2) from the above (Table 1). The chosen trial samples were presented in the forms of:

A. Dry crystals (trial sugar samples in dry crystallised form were served in comparison to normal cane sugar)

B. Aqueous solution (2g of normal cane sugar and test sugar samples were dissolved in $250 \mathrm{ml}$ of water)

C. Tea solution (2g of normal cane sugar and test sugar samples were dissolved in $250 \mathrm{ml}$ of tea solution)

\section{Selection of the best sample}

Successfully crystallised trial samples from the preparation (Table 1) were subjected to sensory evaluation. The best trial sample selected from the sensory analysis (Table 2) was recognised as the most suitable to be commercialised and used for further GI determination.

The commercial product (Product 1) already has a two-year shelf life and is certified with ISO22000. Microbiological tests were carried out to check whether the novel sugar product complied with 
Table 2. Initial brix values and herbal extract ratios of chosen trial samples for sensory analysis ( $\mathrm{x}$ - Trial component)

\begin{tabular}{|c|c|c|c|c|}
\hline \multirow{2}{*}{$\begin{array}{l}\text { Trial sample } \\
\text { number }\end{array}$} & \multirow{2}{*}{$\begin{array}{l}\text { Initial brix value \& } \\
\text { herbal extract ratio } \\
\text { (Gooseberry:Ginger) }\end{array}$} & \multicolumn{3}{|c|}{ Presented form } \\
\hline & & Dry crystalised form & Aqueous solution & With tea \\
\hline 1 & $\begin{array}{l}16^{0} \\
2: 2\end{array}$ & $\mathrm{X}$ & $\mathrm{X}$ & $\mathrm{X}$ \\
\hline 2 & $\begin{array}{l}16^{0} \\
4: 2\end{array}$ & $\mathrm{X}$ & $\mathrm{X}$ & $\mathrm{X}$ \\
\hline 3 & $\begin{array}{l}16^{0} \\
6: 2\end{array}$ & $\mathrm{X}$ & $\mathrm{X}$ & $\mathrm{X}$ \\
\hline 4 & $\begin{array}{l}16^{0} \\
8: 2\end{array}$ & $\mathrm{X}$ & $\mathrm{X}$ & $\mathrm{X}$ \\
\hline 5 & $\begin{array}{l}17^{0} \\
4: 2\end{array}$ & $\mathrm{X}$ & $\mathrm{X}$ & $\mathrm{X}$ \\
\hline 6 & $\begin{array}{l}17^{0} \\
8: 2\end{array}$ & $\mathrm{X}$ & $\mathrm{X}$ & $\mathrm{X}$ \\
\hline
\end{tabular}

the Principles for the Establishment and Application of Microbiological Criteria for Foods, CAC/GL 21-1997 (CAC, 1997), Codex Standard for Sugar, CODEX STAN 212-1999 (CAC, 1999).

\section{Intervention}

Selection of study subjects for intervention Healthy adults aged 20-45 years old with a body mass index (BMI) of 18.5$23.5 \mathrm{~kg} / \mathrm{m}^{2}$, normal fasting blood glucose level (overnight fast of 8-12 hours) and who wished to voluntarily participate in this experiment were selected. Subjects without recent past history of chronic diseases and without present medical complaints were selected while maintaining gender balance (six males and six females). If the selected volunteer was pregnant, breastfeeding, intolerant or allergic to any of the foods, had problems such as consuming reference or test food samples, abnormalities in blood glucose responses or was not interested to give blood due to time limitation because of his/her lifestyle, then the volunteer was not considered for the study.
Feeding of the test food

According to the World Health Organization/Food and Agriculture Organization of the United Nations recommendations (FAO/WHO, 1998), there is a designated method used for measuring GI. Subjects were asked to report each testing session after an 8-12 hours overnight fast, to avoid cycling or walking to the laboratory and to not consume unusually large meals, drink alcohol or exercise vigorously on the previous day. In the first two sessions, subjects were given the standard reference food of glucose $(\mathrm{D}(+)-$ Glucose) In the next sessions, tested sugar products were given to them (each item was given twice), and they were requested to consume the foods within 15 minutes.

The amount of sugar and glucose per solution was determined according to the digestible carbohydrate content of the relevant materials and solutions that were made out of them, each containing $300 \mathrm{ml}$. Solutions were prepared so that each of them contained $50 \mathrm{~g}$ of digestible carbohydrates. Calculation for $50 \mathrm{~g}$ of 
available carbohydrate content is as follow:

Required amount $(\mathrm{g})=$

$$
\frac{50}{(100-\mathrm{M}) \times \mathrm{X}}
$$

M: \% Moisture content

X: \% Available carbohydrate content

\section{Blood collection}

This intervention/human study was carried out particularly under the supervision of a medical doctor, a biochemist and a well-trained technical officer. Surface of the blood drawing environment was cleaned with ethanol and only sterilised needles were used for drawing blood. Each time when blood had to be drawn, the finger tips of participants were cleaned with ethyl alcohol before and after pricking.

Finger prick blood samples were obtained at 15-30 minutes intervals over the next two hours after the meal (at times $0,15,30,45,60,90,120$ minutes; the beginning of the food intake was time 0). Samples were centrifuged at 7000rpm for ten minutes, and the serum was separated and was kept in refrigerated conditions until analysis.

\section{Biochemical analysis}

Concentrations of the blood glucose samples collected were determined by colorimetric method using glucose oxidase-peroxidase enzyme; with the use of Pap fluid glucose oxidase kit (BiolaboFrance). Serum $(10 \mu \mathrm{L})$ was transferred to a clean, dry test tube with addition of the reagent $(1 \mathrm{~mL})$, followed by incubation in a water bath $\left(37^{\circ} \mathrm{C}, 10\right.$ minutes). Two replicates of each serum sample were used. Absorbance values for all samples were measured against a reagent blank, using Systronic spectrophotometer (modal: UVmini-1240, Serial NoA10934703413 CD, Japan).

The GI of the products were calculated according to the method of Jenkins et al. (1981). The values of serum glucose concentrations were plotted against time at time 0 , after 30,60 and 120 minutes intervals after consumption of the reference food and test food for each individual. For each person, the incremental area under his/her blood glucose response [glucose incremental area under the curve (IAUC)] and for the tested sugar product (Product 1 or Product 2) was then measured by the trapezoidal rule (the sum of the surface of trapezoids between the blood glucose curve and horizontal baseline going parallel to $\mathrm{x}$ axis from the beginning of blood glucose curve at time 0 to the point at time $120 \mathrm{~min}$ to reflect the total rise in blood glucose concentration after consumption of a particular food).

Then, the individual's glucose IAUC for the test food was divided by his/ her glucose IAUC for the reference food and the GI value for the test food was calculated for each person. The final GI value for each test food was the mean GI value of the 12 people for the respective product.

GI was calculated by the formula:

$$
\mathrm{GI}=\frac{\text { IAUC for the test food }}{\text { IAUC for the standard }} \times 100
$$

(Brand-Miller JC, 2003; Jenkins et al., 1981)

\section{Statistical analysis}

In sensory analysis, sugar samples were presented in the forms of dry crystals, aqueous solution and with tea. Hence, descriptive analysis were done for these three forms separately. The Friedman test, which is the non-parametric alternative to the one-way analysis of variance (ANOVA) with repeated measures was used since the test was for differences between groups when the dependent variable being measured is ordinal and for continuous data that has 
violated the assumptions necessary to run the one-way ANOVA with repeated measures (e.g. data that has marked deviations from normality).

In GI calculations, IAUC of individual blood glucose responses were calculated by Microsoft Excel 2013. GI value and standard deviation values of each individual for each tested sugar product and for glucose were calculated using the same software at $95 \%$ confidence interval (CI). Comparison of GI values between commercial cane sugar and the two sugar substitute products was done using unpaired two tailed $t$-test (Microsoft Excel 2013) and Q-test was performed to identify existing outliers among the volunteers.

\section{RESULTS AND DISCUSSION}

\section{Preparation of novel sugar product and sensory analysis}

The initial sugar solutions were odourless and colourless at room temperature $\left(29^{\circ} \mathrm{C}\right)$. When heating temperature of the solutions increased, thickness of the solutions increased too. At $115^{\circ} \mathrm{C}$, Phyllanthus and Zingiber extracts were incorporated and solutions were allowed to cool down to solidify.

Solutions with higher initial brix values were solidified before adding ginger extract due to higher solid content. Solutions with lower initial brix values or higher herbal extract volumes were not solidified. According to the results observed, suitable initial brix values and herbal extract ratios were chosen for the sensory analysis (Table 2).

According to the microbiological test results, Product 2 (novel sugar product) was confirmed to be in accordance with the Principles for the Establishment and Application of Microbiological Criteria for Foods (CAC/GL 21-1997) and was therefore suitable for human consumption.

According to the test results, there were no significant differences $(p>0.05)$ observed (CI 95\%) in the appearance, odour, colour and taste attributes between the six trial samples presented in aqueous solutions, with tea and in dry form; although it was demonstrated that (CI 95\%) there was a significant difference between $(p<0.05)$ the overall acceptability and considering sum of ranks. The best sample was chosen and used for the determination of GI.

\section{Determination of glycaemic indices}

From the initially selected 15 individuals, only 13 were finally selected into this study. From that group, one was released due to abnormalities in blood glucose responses. To maintain the gender balance in this study, six males and six females were selected.

Glucose oxidase method was the most suitable method to determine blood glucose concentration accurately. Glucose oxidase (GOD) converted the sample glucose into gluconate. The hydrogen peroxide $\left(\mathrm{H}_{2} \mathrm{O}_{2}\right)$ produced in the reaction was degraded by peroxidase (POD) and gave a coloured product phenol and 4-aminoantipyrine, which was measurable using Trinder indicator reaction at $505 \mathrm{~nm}$. The increase in absorbance correlated with the glucose concentration of the sample (Bjorkhem et al, 1976).

Glucose $+\mathrm{O}_{2} \stackrel{\text { GOD }}{\longrightarrow}$ Gluconic acid $+\mathrm{H}_{2} \mathrm{O}_{2}$
$2 \mathrm{H}_{2} \mathrm{O}_{2}+$ Phenol+4-
Aminoantipyrine $\stackrel{\text { POD }}{\longrightarrow} \begin{gathered}\text { Red quinone+4 } \\ \mathrm{H}_{2} \mathrm{O}\end{gathered}$

If any red blood cells remained in the serum sample, it will absorb the glucose and may give false results. Interruption 
with higher levels of red blood cells will not give a detectable value at all. After separation, serum sample must be adequate for carrying on further tests. Hence, immediately after collection, blood samples were centrifuged and serum was separated.

When GI values were expressed, the industrially made low GI sugar product demonstrated a GI value of $49 \pm 9$ and the GI value of the novel sugar product was 38 9 . A significant difference $(p<0.05)$ was observed between the GI values of these two sugar products (Table 3 ).

The GI in Product 1 decreased from 65.0 to 49.9 (Table 3) with respect to normal cane sugar. When considering the novel product (Product 2), the decrease in GI was far greater; from 65.0 to 38.5 (Table 3$)$. A significant $(p<0.05)$ decrease in the GI of both sugar products was observed compared to cane sugar.

Among the volunteers, $100 \%$ had elicited low GI values for both sugar products compared to normal cane sugar (Table 3). All 12 volunteers (six males and six females) were fed with both sugar products and 100\% of them elicited low GI values for the novel product (Product 2) compared to the commercially available Product 1 (Table 3).

The average percentage of GI reduction for Product 1 was $23.2 \pm 13.3 \%$, while the novel sugar product (Product 2) showed a higher GI reduction of $40.8 \pm 13.7 \%$ (Table 3).

When $Q$-test was used for the individual GI values of the volunteers, no outliers were found, confirming that all 12 data obtained for GI were valid. According to the statistical analysis, there were no significant differences observed in the mean GI values between males and females and across different age groups.

When the mode of peaking times is concerned, a much faster peaking time was visible in both sugar products and their peaking times shifted from 45 minutes to 30 minutes compared to the reference glucose (Table 4). With the observed values, there is a probability for peaking time to increase in both sugar products, within a larger sample. Both the commercialised low GI sugar product and the novel sugar product showed the same peaking time of 30 minutes.

Table 3. Individual glycaemic indices and percentage GI reduction

\begin{tabular}{ccccc}
\hline \multirow{2}{*}{ Volunteer } & \multicolumn{3}{c}{ Product 1 } & \multicolumn{3}{c}{ Product 2 } \\
\cline { 2 - 5 } & GI for Product 1 & \% GI Reduction & GI for Product 2 & \% GI Reduction \\
\hline 1 & 45.4 & 30.1 & 36.8 & 43.4 \\
2 & 37.8 & 41.8 & 33.4 & 48.7 \\
3 & 52.5 & 19.3 & 17.8 & 72.7 \\
4 & 45.1 & 30.7 & 45.0 & 30.8 \\
5 & 58.2 & 10.5 & 43.7 & 32.7 \\
6 & 56.6 & 13.0 & 41.1 & 36.7 \\
7 & 56.7 & 12.7 & 32.0 & 50.7 \\
8 & 67.3 & -3.60 & 46.6 & 28.4 \\
9 & 46.3 & 28.7 & 29.1 & 55.3 \\
10 & 49.5 & 23.8 & 46.0 & 29.2 \\
11 & 38.9 & 40.2 & 44.1 & 32.2 \\
12 & 44.9 & 30.9 & 46.1 & 29.2 \\
Mean & 49.9 & 23.2 & 38.5 & 40.8 \\
SD & 8.6 & 13.3 & 8.9 & 13.7 \\
\hline
\end{tabular}


Table 4. Peak serum glucose concentrations and peaking times of individuals as observed in respective glucose response curves

\begin{tabular}{ccccccc}
\hline \multirow{2}{*}{ Volunteer } & \multicolumn{2}{c}{ Glucose } & \multicolumn{2}{c}{ Product 1 } & \multicolumn{2}{c}{ Product 2 } \\
\cline { 2 - 7 } & $\begin{array}{c}\text { Time } \\
(\mathrm{min})\end{array}$ & $\begin{array}{c}\text { Concentration } \\
(\mathrm{mg} / \mathrm{dL})\end{array}$ & $\begin{array}{c}\text { Time } \\
(\mathrm{min})\end{array}$ & $\begin{array}{c}\text { Concentration } \\
(\mathrm{mg} / \mathrm{dL})\end{array}$ & $\begin{array}{c}\text { Time } \\
(\mathrm{min})\end{array}$ & $\begin{array}{c}\text { Concentration } \\
(\mathrm{mg} / \mathrm{dL})\end{array}$ \\
\hline 1 & 45 & 125 & 30 & 107 & 15 & 99 \\
2 & 45 & 165 & 15 & 119 & 30 & 120 \\
3 & 30 & 139 & 30 & 127 & 30 & 115 \\
4 & 45 & 186 & 30 & 153 & 30 & 160 \\
5 & 30 & 125 & 30 & 148 & 30 & 115 \\
6 & 45 & 153 & 45 & 126 & 15 & 108 \\
7 & 30 & 135 & 15 & 164 & 30 & 108 \\
8 & 45 & 194 & 45 & 144 & 45 & 157 \\
9 & 45 & 132 & 45 & 140 & 30 & 117 \\
10 & 30 & 152 & 45 & 151 & 15 & 134 \\
11 & 15 & 143 & 30 & 142 & 30 & 134 \\
12 & 45 & 177 & 45 & 145 & 30 & 125 \\
Mode & 45 & & 30 & & 30 & \\
Mean & & 152 & & 139 & & 124 \\
\hline
\end{tabular}

The peak serum glucose concentration significantly decreased $(p>0.05)$ from the reference glucose (152) to the commercialised low GI sugar product (139), and from the reference glucose (152) to the novel sugar product (124) (Table 4). This proves the effect of herbal extracts in decreasing immediate blood glucose response. Though the two sugar products had similar peaking times, the peak serum glucose concentration in the novel sugar product (124) was lower than the commercialised low GI sugar product (139).

As for individual incremental area under the curve for sugar products, the maximum peaking time was similar (30 minutes) in both sugar products,

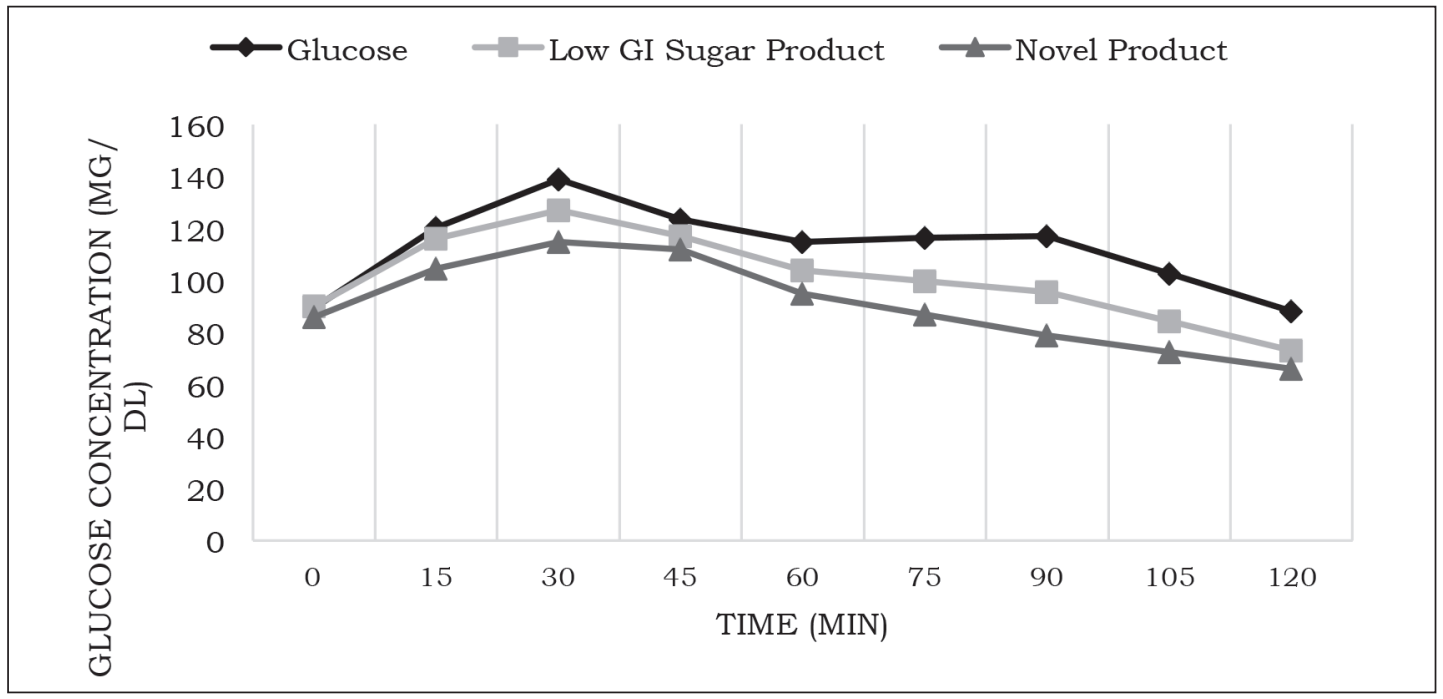

Figure 1. Incremental area under the curve for sugar products 
as well as in cane sugar (Figure 1). Accordingly, the decrease in peak serum glucose concentration with respect to GI of the sugars was visible. The commercialised low GI sugar product (GI=49) had the highest peak in serum glucose concentration, while the novel sugar product $(\mathrm{GI}=38)$ had the lowest between the two sugar products. The peak reduction of the newly formulated product (Product 2) and its continued lowering of blood glucose levels was clearly visible during the two-hour period (Figure 1).

These incorporated herbal extracts contain a variety of active phytochemicals, including flavonoids, terpenoids, lignans, sulfides, polyphenolics, carotenoids, coumarins, saponins, plant sterols, curcumins, and phthalides. Due to the presence of bioactive compounds in them, several biological activities of these spices, such as antioxidants, anti-diabetes, antihyperlipidemic, or anti-hypertension, have been reported and validated (Susila et al., 2017). Furthermore, these compounds are known to have a variety of health \& wellness characteristics such as inhibiting cyclooxygenase enzymes, improving metabolism and enhancing insulin sensitivity, therefore can be the reasons for reduced GI values observed in these sugar products (Upasani et al., 2013).

Although there was a significant difference in the average GI values of the two sugar products, the percentage in GI reduction of the novel sugar product was much lower (40.8\%) compared to the $23.2 \%$ GI reduction observed in the commercialised low GI sugar product. Therefore, the difference in incorporated volume and raw materials of the herbal extracts (quantity and quality) should be the logical factor affecting this significant difference in the GI between these two products. There is still insufficient evidence to draw definitive conclusions about the efficacy of individual herbs on glycaemic impact. However, they appear to be generally safe. Although both products contained gooseberry and ginger, the new product contained only these two, but in larger proportions. They have resulted in a better GI reduction, proving that gooseberry and ginger together have greater effects on reducing glycaemic impact than the rest of the five ingredients added in the commercial product.

According to the above study, the blood glucose response and peak serum concentration were relatively lower in cane sugar products incorporated with herbal extracts. Therefore, they are more suitable for consumption among people having issues related to diabetes and hyperglycaemia. Furthermore, encouraging the incorporation of suitable herbal extracts to foods like rice and wheat flour may be suitable options for individuals with the same health issues. Rather than using expensive raw materials, introducing substitute products using under-utilised native resources have several advantages, both from the financial and social perspectives.

\section{CONCLUSION}

The GI values of both sugar products incorporated with herbal extracts were significantly lower $(p<0.05)$ with respect to normal cane sugar, which was a decrease from the high GI category to the low GI food category. The GI of the novel sugar product (Product 2) was significantly lower $(p<0.05)$ than that of the commercially available product (Product 1). Hence, it is possible to conclude that Phyllanthus emblica and Zingiber officinale are superior in reducing blood glucose responses compared to many other known herbs. 


\section{Acknowledgement}

The authors would like to thank all the volunteers who generously shared their time; Laboratory assistants Mrs Somachandra HS \& Mr. Ruwansiri T, for providing assistance; Dr. Etampawala TNB, Dr. Rajapaksha AU, Dr. Walpita JK and other staff members of Instrument Centre, Faculty of Applied Sciences, University of Sri Jayewardenepura for providing guidance in blood sample analysing.

\section{Authors' contributions}

CHS, principal investigator, conceptualised and designed the study, led the development of the novel sugar product, conducted the study, data analysis and interpretation, prepared the draft of the manuscript and reviewed the manuscript; MAJ, advised on study design, assisted in developing the novel sugar product, data analysis and interpretation and reviewed the manuscript; SPASS, advised on study design and reviewed the manuscript; IW, assisted in developing the novel sugar product and reviewed the manuscript; $\mathrm{BF}$, assisted in drafting of the manuscript, reviewed the manuscript; KKDSR, reviewed the manuscript; NHBW, assisted in data analysis and interpretation and reviewed the manuscript.

\section{Conflict of interest}

The authors declare no conflict of interest.

\section{References}

Akhtar MS, Ramzan A, Ali A \& Ahmad M (2011). Effect of amla fruit on blood glucose and lipid profile of normal subjects and type 2 diabetic patients. Ind J Food Sci Nutr 62(6):609-616.

Andallu B, Radhika B \& Suryakantham V (2003). Effect of aswagandha, ginger and mulberry on hyperglycemia and hyperlipidemia. Plant Food Hum Nutr 58:1-7.

Bjorkhem I, Blomstrand R, Falk O \& Ohman G (1976). The use of mass fragmentography in the evaluation of routine methods for glucose determination. Clin Chem Acta (72):353-362.

Brand-Miller JC (2003). Glycemic load and chronic disease. Nutr Rev 61(5 pt 2):S49-55.

CAC (1997). Principles for the Establishment and Application of Microbiological Criteria for Foods. CAC-GL 21-1997 Joint FAO/WHO Food Standards Program. Codex Alimentarius Commission, Food and Agriculture Organization of the United Nations, Rome.

CAC (1999). CODEX STAN 212-1999, CODEX Standards for Sugars. Joint FAO/WHO Codex Alimentarius International Food Standards. Codex Alimentarius Commission, Food and Agriculture Organization of the United Nations, Rome.
Chockaligam A, Rao D, Sarikonda S, Reddy K, Reddy D, Chidambaram N, Saravanan N, Janaki CS \& Rajalakshmi (2018). Effect of Diabliss herbal sugar (DHS) in patients with type-II diabetes mellitus. Int $J$ Diabetes Res $7(2): 31-35$.

Choudhari SS \& Kareppa BM (2013). Identification of bioactive compounds of Zingiber officinale roscoe rhizomes through gas chromatography and mass spectrometry. Int $J$ Pharm Res Dev 5:16-20.

Daisy PH, Averal RD \& Modilal (2005). Curative properties of Phyllanthus extract in alloxaninduced diabetic rats. J Trop Med Plant 5:2127.

Eleazu CO (2016). The concept of low glycemic index and glycemic load foods as panacea for type 2 diabetes mellitus; prospects, challenges and solutions. Afri Health Sci 16(2):468-479.

FAO/WHO (1998). Carbohydrates in Human Nutrition. FAO Food and Nutrition Paper 66. Food and Agriculture Organization of the United Nations, Rome.

Goldenberg R \& Punthakee Z (2013). Definition, classification and diagnosis of diabetes, prediabetes and metabolic syndrome. Can $J$ Diabetes (37):S8-S11.

Gunathilaka SS \& Ranaweera KDS (2018). Determination of glycaemic responses of low fat milk incorporated with whey proteins and oats powder. J Clin Nutr 4(2):8.

ISO (2003). BS ISO 13299:2003. Sensory AnalysisMethodology - General Guidance for Establishing a Sensory Profile. International Organization for Standardization, Geneva.

Jenkins DJ, Wolever TM, Taylor RH, Barker $\mathrm{H}$, Fielden $\mathrm{H}$, Baldwin JM, Bowling AC, Newman HC, Jenkins AL \& Goff DV (1981). Glycemic index of foods: a physiological basis for carbohydrate exchange. Am $J$ Clin Nutr (34):362-6.

Katulanda P, Sheriff M \& Matthews D (2009). The diabetes epidemic in Sri Lanka - a growing problem. Ceylon Med J 51(1):26-28.

Kharroubi AT \& Darwish HM (2015). Diabetes mellitus: The epidemic of the century. World $J$ Diabetes 6(6):850-67.

Kumara MDR \& Siriwardena PR (2016). Knowledge, attitudes and practices regarding physical activities among patients with type 2 diabetes. Sri Lanka Journal of Diabetes Endocrinology and Metabolism 6(1):13-17. 
Modak M, Dixit P, Londhe J, Ghaskadbdi S \& Devasagayam TPA (2007). Indian herbs and herbal drugs used for the treatment of Diabetes. J Clin Biochem Nutr 40(3):163-173.

Patel SS \& Goyal RK (2011). Prevention of diabetesinduced myocardial dysfunction in rats using the juice of the Emblica officinalis fruit Exp Clin Cardiol 16(3):87-91.

Röder PV, Wu B, Liu Y \& Han W (2016). Pancreatic regulation of glucose homeostasis. Exp Mol Med 11:48:e219.

Röhrig B, du Prel JB, Wachtlin D, Kwiecien R \& Blettner M (2010). Sample size calculation in clinical trials: part 13 of a series on evaluation of scientific publications. Dtsch Arztebl Int 107(31-32):552-556.

Shah KV, Tirgar PR, Patel VP, Desai TR \& Goyal RK (2005). Investigation into mechanism of action of antidiabetic activity of Emblica officinalis on streptozotocin induced type I diabetic rat. Res J Pharma Biol Chem Sci 1(4):672-682.

Sullivan L (2019). In: Power and Sample Size Determination. From http://sphweb.bumc. bu.edu / ot1t / MPH-Modules / BS / BS 704 Power/BS704_Power_print.html [Retrieved June 2 2019].
Suryanarayan P, Saraswat M, Petrash JM \& Reedy GB (2007). Emblic officinalis and its enriched tannoids delay stertozotocin-induced diabetic cartaract in rats. Mol J Vis 24(13):1291-7.

Susila R, Gladys RJ, Arunadevi R, Jothi J, Arunachalam C \& Balagurusamy K (2017). A review on anti-diabetic herbs of Siddha system with special reference to it's organoleptic quality (taste) as per tridosam concept. Int $J$ Herb Med 5(5):97-101.

Upasani SV, Ingle PV, Patil PH, Nandedkar RY, Shah VS \& Surana SJ (2013). Traditional Indian spices useful in Diabetes Mellitus - an updated review. JPBS 4:157-161.

Valitutto M (2008). Common crossroad in diabetes management. Osteopath Med Prim Care 2(1):4.

Wrolstad RE (2011). Sugar Composition of Foods. Food Carbohydrate Chemistry 23-33. 